STUDI

FRANCESI

\section{Studi Francesi}

Rivista quadrimestrale fondata da Franco Simone

142 (XLVIII | I) | 2004

Varia - fasc. I - gannio-aprile 2004

\title{
1836. L'An I de l'ère médiatique. Analyse littéraire et historique de «La Presse» de Girardin, sous la direction de Marie-Ėve Therenty et Alain Vaillant
}

\section{Catherine Gaviglio Faivre D'arcier}

\section{(2) OpenEdition Journals}

Édition électronique

URL : https://journals.openedition.org/studifrancesi/40837

DOI : $10.4000 /$ studifrancesi.40837

ISSN : 2421-5856

Éditeur

Rosenberg \& Sellier

\section{Édition imprimée}

Date de publication : 1 juillet 2004

Pagination : 203-204

ISSN : 0039-2944

\section{Référence électronique}

Catherine Gaviglio Faivre D'arcier, « 1836. L'An I de l'ère médiatique. Analyse littéraire et historique de «La Presse» de Girardin, sous la direction de Marie-Ėve Therenty et Alain Vaillant », Studi Francesi [En ligne], 142 (XLVIII | I) | 2004, mis en ligne le 30 novembre 2015, consulté le 09 septembre 2021. URL : http:// journals.openedition.org/studifrancesi/40837 ; DOI : https://doi.org/10.4000/studifrancesi.40837

Ce document a été généré automatiquement le 9 septembre 2021.

\section{c)}

Studi Francesi è distribuita con Licenza Creative Commons Attribuzione - Non commerciale - Non opere derivate 4.0 Internazionale. 


\title{
1836. L'An I de l'ère médiatique. Analyse littéraire et historique de «La Presse» de Girardin, sous la direction de Marie- Ève Therenty et Alain Vaillant
}

\author{
Catherine Gaviglio Faivre D'arcier
}

\section{RÉFÉRENCE}

AA. VV., 1836. L'An I de l'ère médiatique. Analyse littéraire et historique de «La Presse» de Girardin, sous la direction de Marie-Ève THERENTY et Alain VAILLANT, Nouveau Monde Éditions, 2001, pp. 388.

1 Avec l'apparition d'un nouvel organe de presse lancé par Émile de Girardin, l'année 1836 marqua une révolution dans le monde des lettres: le livre semblait dépassé et la littérature sur sa fin. L'aspect économique de cette révolution, bien connu, a tendance à masquer une volonté clairement affirmée de médiation des échanges au sein de l'espace public, à laquelle est liée la double émergence d'un nouveau type d'auteur et d'une nouvelle poétique journalistique.

2 À la révolution historique et littéraire correspond une démarche scientifique novatrice. Les auteurs de ce volume ont choisi d'étudier, non pas la littérature à travers un périodique, mais le journal lui-même comme objet littéraire. Un tel projet explique le choix de «La Presse», en raison de son caractère généraliste. Par ailleurs, afin de mettre au point un protocole d'analyse applicable à d'autres périodiques et de gagner une connaissance concrète du journal par une double immersion dans l'époque et dans le corpus considéré, seule la première année de publication a été retenue.

3 Après avoir replacé le projet éditorial de Girardin dans le contexte historique et journalistique de l'époque (où il apparaît que la révolution résidait moins dans l'invention de nouvelles formes du journal que dans l'adaptation des anciennes à une 
plus grande échelle), après avoir décrit minutieusement leur objet d'étude matériellement, les auteurs livrent les résultats de leur lecture en continu du journal du $1^{\mathrm{er}}$ juillet 1836 au 30 juin 1837.

4 Examinée à la loupe, l'année 1836, anodine en apparence, se révèle d'une étonnante complexité, riche en péripéties dans les domaines économiques et politiques. Sur cette toile de fond, Girardin, au premier plan, expose avec conviction sa conception de la presse comme un pouvoir à part entière. Il fait de la reconnaissance et de la construction du champ économique et politique, ainsi que du travail comme vecteur démocratique, deux chevaux de bataille. Dans le domaine culturel, le journal compose avec les préoccupations bourgeoises de son public, tout en réclamant la reconnaissance des "producteurs culturels»; en matière de critique, il s'inscrit dans la polémique relative à l'indépendance des lettres face aux transformations industrielles de la presse. Enfin, Delphine de Girardin, sous le pseudonyme de vicomte de Launay, fonde durablement la fonction de chroniqueur, qui façonne l'identité du journal.

5 Au-delà de l'unité de ton donnée par la personnalité de son fondateur et par celle de sa femme, «La Presse», bien que structurée par diverses rubriques, offre une information éclatée, polyphonique et mouvante. La chronique judiciaire, au contenu hétéroclite, hésite entre débat et chronique. La thématique de la presse, vaste matière à polémiques, se rapproche du feuilleton par son caractère ouvert. La publicité adopte une écriture qui prête à confusion avec celle du journalisme. La fiction, loin de se cantonner dans le seul cadre du feuilleton (au canon duquel le roman de Dumas, Pascal Bruno, répond bien plus que La Vieille Fille de Balzac), se répand en haut et en bas de page. Les faits divers, «forme de l'informe», relèvent d'une esthétique de la mosaïque.

6 Malgré les tâtonnements de sa formule éditoriale, «La Presse» se révèle ainsi un extraordinaire espace de liberté et d'invention, propice à l'émergence d'une nouvelle poétique journalistique portée par une dynamique de la prolifération. Et l'écrivain journaliste, nouveau venu sur la scène littéraire, devient acteur d'une transformation majeure du monde culturel: le passage de l'ère de l'éloquence à celle de la médiatisation.

7 Cette étude fouillée de «La Presse» n'a pas pour vocation de rester isolée. Aussi s'accompagne-t-elle d'annexes qui, au-delà de la bibliographie, d'un index biographique des journalistes et d'un mémento historique sur la législation sur la presse au XIX ${ }^{\mathrm{e}}$ siècle, invite à un large partage du travail. Des témoignages de chercheurs littéraires, spécialistes de la presse, confirment l'intérêt d'une exploitation systématique des corpus: combien de richesses et de surprises malgré l'extrême aridité du travail! Surtout ils posent des questions de méthode, auxquelles le présent ouvrage répond déjà de façon concrète en détaillant les techniques de dépouillement utilisées grâce à la création d'une base de données.

8 La mise au point de protocoles d'analyse communs et une collaboration élargie devraient permettre d'écrire un jour une histoire littéraire de la presse au XIX ${ }^{\mathrm{e}}$ siècle. 